\title{
Study on the Effects of Liquid Thermal Media on the Irradiation Capsule of High-Temperature Materials
}

\author{
Man Soon Cho, Sung Ryul Kim, Seong Woo Yang, and Kee Nam Choo
}

Korea Atomic Energy Research Institute, Daejeon 305-353, Republic of Korea

Correspondence should be addressed to Man Soon Cho; mscho2@kaeri.re.kr

Received 4 June 2015; Revised 10 August 2015; Accepted 10 August 2015

Academic Editor: Eugenijus Ušpuras

Copyright ( 2015 Man Soon Cho et al. This is an open access article distributed under the Creative Commons Attribution License, which permits unrestricted use, distribution, and reproduction in any medium, provided the original work is properly cited.

\begin{abstract}
Irradiation tests of materials at HANARO have usually been conducted using a standard capsule at temperatures of about $300^{\circ} \mathrm{C}$ for irradiation of materials used at PWR. Thus, the standard capsule uses aluminum as the specimen holder, which acts to dissipate the thermal energy. Future nuclear systems such as a VHTR and SFR require the irradiation tests at a relatively high temperature. As an alternative to aluminum which has been used as the thermal media in a standard material capsule, the characteristics of liquid metals such as $\mathrm{NaK}$ and LBE are reviewed. The temperatures of the capsule are affected by the variation of parameters such as the gap and wall thickness of the container. In particular, the external gap is most important in determining the temperature of the specimen. LBE raises the temperature of the specimen higher than NaK at the same configuration of the capsule. Thus, LBE can lessen the gap of the parts and reduce the vibration for a stable long-term test in reactor.
\end{abstract}

\section{Introduction}

Nuclear systems have evolved in accordance with concerns over energy resource availability, climate change, and energy security. Among them, Gen-IV nuclear systems are in the spotlight as future energy sources. Sustainability, safety, costeffectiveness, and proliferation risk reduction for future commercial development are pursued [1], which includes an SCWR (super critical water reactor), SFR (sodium-cooled fast reactor), GFR (gas-cooled fast reactor), LFR (lead-cooled fast reactor) [2], MSR (molten salt reactor), and VHTR (very high temperature reactor) [3]. As VHTR and SFR projects are presently being carried out as a part of the Gen-IV program in Korea [4], the requirements for the irradiation of materials at a relatively high temperature have recently been gradually increased.

To meet these requirements, a new type of capsule is being developed at HANARO. The irradiation tests of the materials at HANARO up to the present have been performed usually at temperatures below $300^{\circ} \mathrm{C}$ under which the RPV (Reactor Pressure Vessel) materials of a PWR are being operated [5]. Currently, various capsules have been developed and are being utilized for the irradiation of materials as well as for a study of the creep and fatigue behaviors and fuel characteristics under irradiation [6]. The material capsules used at HANARO consist of standard, advanced, and rabbit capsules. The standard material capsule is used for basic research of the irradiation effects of materials such as the pressure vessel, reactor core of the PWR, and high-tech materials. The advanced capsule is a device used to measure the changes in the properties of a nuclear material or fuel and control the irradiation conditions during an irradiation test. The rabbit capsule is a small and noninstrumented capsule for use in short and simple irradiation [7].

The standard material capsule has a simple shape containing the specimen holders in a sealed tube. The external tube is made of stainless steel to have enough strength to withstand an external impact when it is installed in the irradiation holes in the reactor, but the specimen holders are usually made of aluminum to process the specimen holes and instrument grooves easily on the surface. The specimen holder plays a role of thermal media to dissipate heat generated in the reactor well. The specimen holder of a standard capsule usually has 4 specimen holes that are arranged at a 90 degree angle at the same distance from the center. However, 


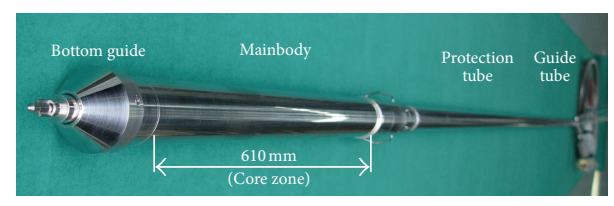

FIGURE 1: Instrumented capsule for the material irradiation test.

the aluminum specimen holder cannot be used at the hightemperature irradiation capsule owing to the low melting point, and thus another material is being sought out. Liquid metal has been accepted as an alternative way for use in an application of high-temperature irradiation for Gen IV reactor material development. And thus, liquid metal such as $\mathrm{NaK}$ (Sodium Potassium) and LBE (Lead Bismuth Eutectic) is reviewed for use as a material to replace aluminum in capsule $[8,9]$. In this paper, a series of thermal analyses for a new capsule with a liquid thermal media was implemented to study the effects of various design parameters influencing the temperature.

\section{Capsule}

2.1. Capsule with Solid Aluminum Thermal Media. The geometrical shape of the HANARO standard capsule is shown in Figure 1. The main-body is a major part of the capsule in which specimens, instruments, and various components are installed, and it includes an external stainless steel tube with a $56 \mathrm{~mm}$ external diameter, $2 \mathrm{~mm}$ in thickness and $870 \mathrm{~mm}$ in length. The inner structure has a specimen holder made of aluminum, which acts as a thermal medium to dissipate the heat generated in the reactor. The rod tip at the bottom of the main-body is assembled with a receptacle in the reactor core. The protection and guide tube act as a guide for various signal lines such as thermocouples, microheaters, and helium supply tubes up to the control unit on the outside of the reactor. Table 1 represents the geometrical data of the cross section including the specimens.

The specimen holder is a cylinder with four rectangular specimen holes and one circular center hole of $10 \mathrm{~mm}$ in diameter. It has a length of $114 \mathrm{~mm}$ and is used for fixing the test specimens. The five holders in the main-body are arranged in the axial direction, and insulators made of alumina between the holders are placed to prevent heat from transferring between the stages and to control the temperature of each stage independently. Figure 2 shows a schematic view of the standard capsule inside. Usually, 12 thermocouples and 5 microheaters are installed on the specimen holder. The gap between the holder and the specimens is usually $0.1 \mathrm{~mm}$ and that between the holder and the tube is $0.1 \sim 1.0 \mathrm{~mm}$, which is designed to effectively control the temperature of each stage.

2.2. Capsule with Liquid Metal Thermal Media. Since the irradiation tests for the future nuclear systems in an SFR and VHTR will be conducted at a relatively high temperature of 550 to $950^{\circ} \mathrm{C}$ [1], it is desirable to not use aluminum as the thermal media of a high-temperature irradiation capsule
TABLE 1: Geometrical data of the standard capsule.

\begin{tabular}{lc}
\hline Descriptions & Dimension $(\mathrm{mm})$ \\
\hline Outer diameter of the external tube & 56 \\
$\begin{array}{l}\text { Inner diameter of the external tube } \\
\text { Center hole diameter of the holder }\end{array}$ & 52 \\
$\begin{array}{l}\text { Specimen hole size (width } \times \text { height } \times \text { length) } \\
\begin{array}{l}\text { Distance between the center hole and } \\
\text { specimen hole }\end{array}\end{array}$ & $10 \times 10 \times 114$ \\
\hline
\end{tabular}

due to the low melting point. As an alternative material of aluminum, solid metals like $\mathrm{Ti}, \mathrm{Ni}, \mathrm{Mo}$, and $\mathrm{W}$ and liquid metals such as $\mathrm{NaK}$ and LBE are being reviewed at HANARO. In this paper, liquid metals are reviewed for use as the thermal media of a high-temperature irradiation capsule. $\mathrm{NaK}$ is a cooling medium of SFR, and thus it is desirable to conduct an irradiation test in the environment of the $\mathrm{NaK}$ in order to study the irradiation features of SFR materials. However, it is highly reactive with water and may catch fire when exposed to air, and thus it must be handled with special precautions. It is not very desirable to use $\mathrm{NaK}$ at the irradiation test of a capsule.

LBE is a eutectic alloy of lead and bismuth [10] used as a coolant in some nuclear reactors and is a proposed coolant for a lead-cooled fast reactor, as part of the GenIV reactor initiative [11]. LBE has significantly higher boiling points as compared to $\mathrm{NaK}$, and thus it can be operated without risk of coolant boiling at higher temperature and it improves thermal efficiency. In addition, it does not react easily with water or air and has an excellent radiation shield blocking the gamma radiation. Even though LBE is more corrosive to steel than $\mathrm{NaK}$, it is very advantageous to use $\mathrm{LBE}$ rather than $\mathrm{NaK}$ as the liquid thermal media in a capsule. Therefore, LBE is strongly recommended as a liquid thermal media for a high-temperature irradiation capsule instead of aluminum. To use LBE as a thermal media instead of $\mathrm{NaK}$ in the capsule, the effects of both materials exerted at the temperature of the specimens would be evaluated before use at the irradiation test. The overall shape of the capsule with the liquid metal thermal media is quite similar to the present standard material capsule except for use of liquid metal instead of aluminum as the thermal media. The cross sections of the capsules with solid and liquid thermal media are shown in Figure 3.

The capsule is $56 \mathrm{~mm}$ in diameter and $870 \mathrm{~mm}$ long and consists of a specimen container, a liquid metal container, and an external tube. The 4 columns of the specimen holders are placed at 90 degrees to maximize the space. Helium gas is filled into the gap between the container and the external tube and between the specimen and the specimen holder. There are walls and gaps that block the heat transfer out from the specimen to the outside cooling water. They are the wall of the external tube, the specimen container (thickness T1), and the liquid metal container (thickness T2) and the gap (thickness G1) between the specimen and the specimen container and the gap (thickness G2) between the liquid metal container and the external tube. 


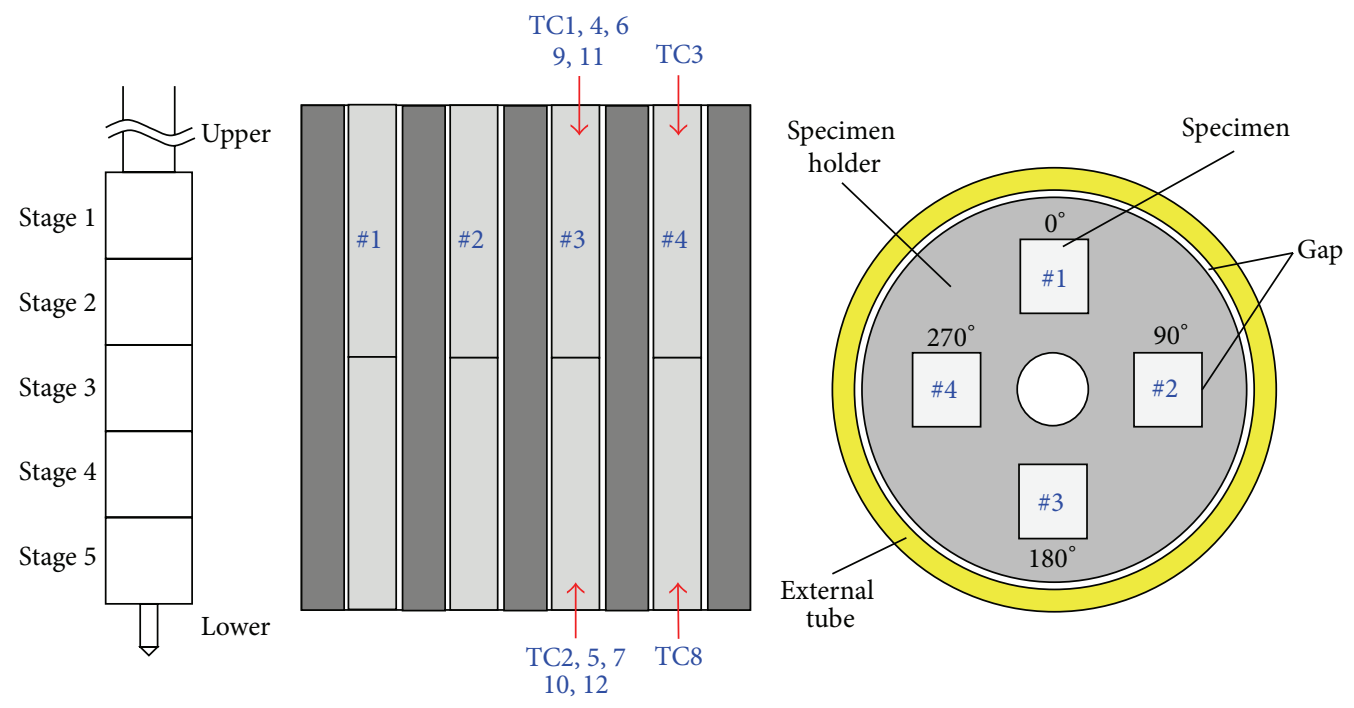

Figure 2: Schematic view of the standard capsule.

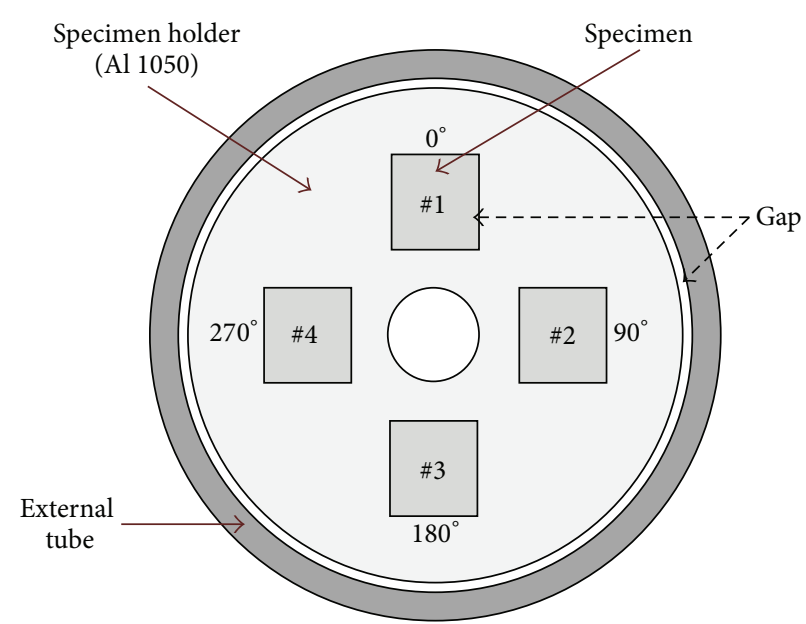

G1: gap between the specimen and the specimen holder G2: gap between the liquid metal container and the external tube

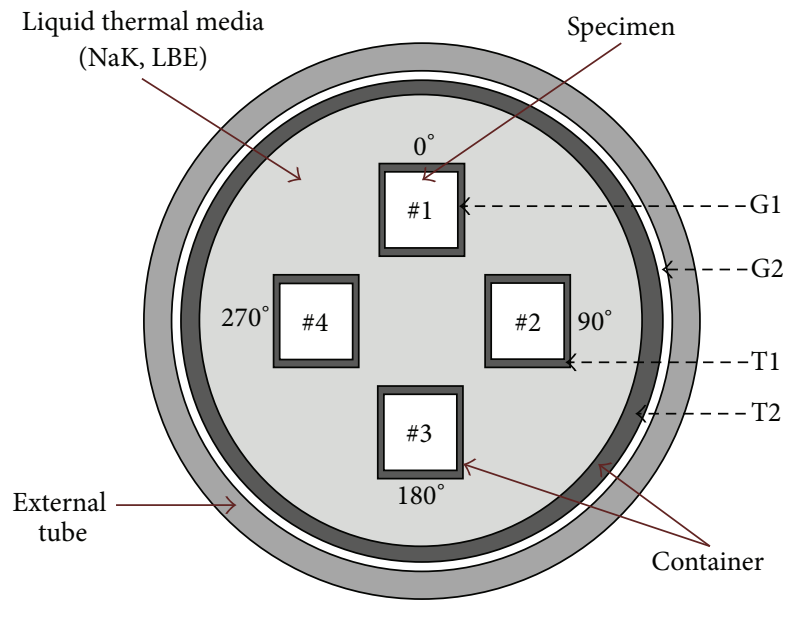

T1: thickness of the specimen container T2: thickness of the liquid metal container

FIGURE 3: Cross sections of capsules with solid and liquid thermal media.

\section{Thermal Analysis}

A temperature analysis for capsules with three kinds of thermal media, that is, aluminum, $\mathrm{NaK}$, and LBE, was performed. The temperature calculation is performed using a finite element analysis program, ANSYS. The two-dimensional model of a quarter-section has two specimens shown in Figure 4. These models consist of four main parts: the specimens (alloy 690), the helium gap, the thermal media (Al $1050 / \mathrm{NaK} / \mathrm{LBE}$ ), and the external tube (STS 316L). The liquid of the capsule using liquid thermal media is contained in the metal container. Helium is filled in the gap between the parts of the capsule and does not move up or down because it is confined to a small limited space and exposed to a constant heat flux. Since the helium in the capsule is confined in a narrow space, the heat convection in the gap can be ignored
[12]. Heat is transferred by conduction from center to the external tube and then is released to the cooling water by convection. There is a helium gap between the inner container and the external tube, in which the temperature falls sharply. In case of a high-temperature irradiation test, the temperature will sharply drop from about $900^{\circ} \mathrm{C}$ to $40^{\circ} \mathrm{C}$ between the inner container wall and the external tube. The radiation heat is emitted from the inner container to the external container in accordance with the Stefan-Boltzmann law. The external tube will absorb the radiation heat and release it to the outer cooling water by convection.

The temperature of cooling water in the reactor in-core is about $40^{\circ} \mathrm{C}$, and the heat transfer coefficient at the outer surface of the external tube is $30.3 \times 10^{3} \mathrm{~W} / \mathrm{m}^{20} \mathrm{C}$, which is experimentally determined [13]. The two conditions above are considered as boundary conditions in the FE analysis, and 


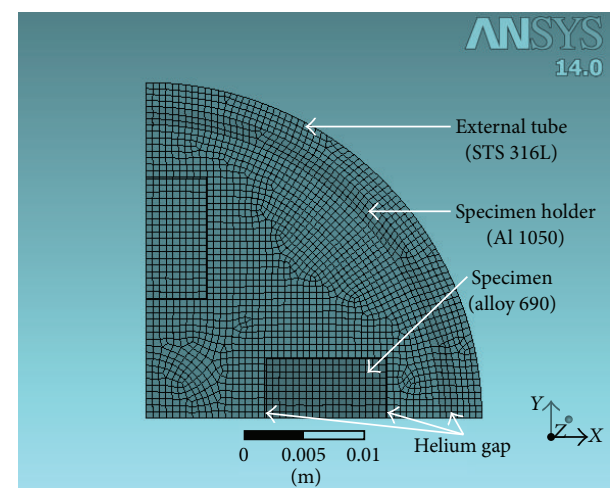

(a)

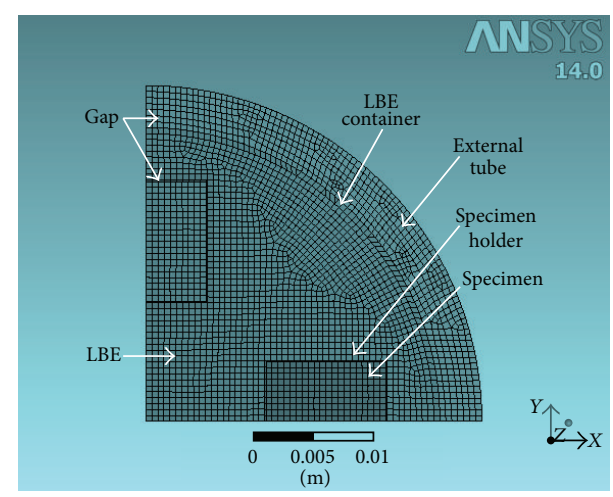

(b)

FIGURE 4: Calculation model ((a) solid thermal media/(b) liquid thermal media).

TABLE 2: Heating rate at OR5.

\begin{tabular}{lcc}
\hline Material & Density $\left(\mathrm{g} / \mathrm{cm}^{3}\right)$ & $\gamma$-heating rate $(\mathrm{W} / \mathrm{g})$ \\
\hline LBE & 9.96 & 1.04 \\
NaK & 0.86 & 1.80 \\
Aluminum & 2.7 & 1.67 \\
Stainless steel & 7.8 & 2.08 \\
\hline
\end{tabular}

the symmetric conditions are also applied for the symmetric axes of the $2 \mathrm{D}$ models. In the reactor, the specimens, the thermal media, and the internal container and the external tube act as heat sources due to $\gamma$ flux. The heating rates of the capsule materials used as the input force in the thermal analysis are listed in Table 2.

The temperature distribution in the capsule depends on the detailed configuration and the thermal environments in which it is placed at the reactor. To evaluate the effect of the design variables such as G1, G2, T1, and T2 relatively, one parameter is varied, while, on the other hand, holding other variables constant. To obtain the thermal characteristics of the liquid thermal media capsule, the gap size of G1 varies from 0.1 to $1.0 \mathrm{~mm}$ and the G2 varies from 0.1 to $1.5 \mathrm{~mm}$; on the other hand, thicknesses $\mathrm{T} 1$ and $\mathrm{T} 2$ of the specimen container and the liquid metal container are considered at the same range from 0.5 to $1.2 \mathrm{~mm}$. The temperature data for a circular cylinder with multiple specimens are obtained by a finite element analysis. The gamma heating rates at the OR5 hole are obtained for a reactor power of $30 \mathrm{MW}$. The boundary conditions in the analysis are symmetric for the $x$ and $y$-axes in the model.

\section{Results and Discussions}

An analysis was conducted to study the effect of variation in the design parameters on the peak temperature of the specimens, the temperature difference within the specimen, and the surface temperature.

4.1. Thermal Characteristics. The results of thermal analyses for capsules with solid and liquid thermal media, in which

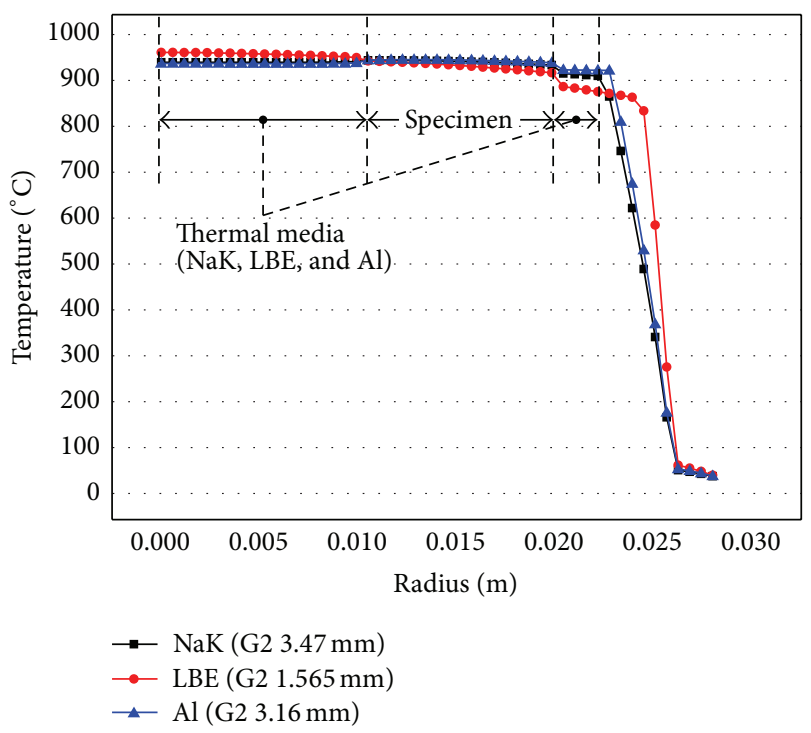

FIGURE 5: Temperature distribution of the capsules with three kinds of thermal media.

the solid thermal media is aluminum and the liquids are $\mathrm{NaK}$ and LBE, are shown in Figure 5. This was aimed at analyzing the characteristics of temperature for a capsule conducting an irradiation test of high-temperature materials to be used in a VHTR in which the coolant is flowing at $950^{\circ} \mathrm{C}$.

When gap G2 in the capsule using LBE thermal media (LBE capsule) is $1.575 \mathrm{~mm}$, the specimen reaches the target temperature of $950^{\circ} \mathrm{C}$, where the values of other variables such as G1, T1, and T2 are fixed. On the other hand, the specimen temperature reaches $950^{\circ} \mathrm{C}$ when gap G2 in the capsule using $\mathrm{NaK}$ thermal media ( $\mathrm{NaK}$ capsule) becomes $3.48 \mathrm{~mm}$, and the specimen reaches $950^{\circ} \mathrm{C}$ when gap G2 in the capsule using aluminum thermal media (Al capsule) is $3.175 \mathrm{~mm}$.

In the aluminum capsule, when the specimen temperature reaches $950^{\circ} \mathrm{C}$, aluminum thermal media would reach a similar temperature. This temperature exceeds the melting point of aluminum, and therefore aluminum cannot be 

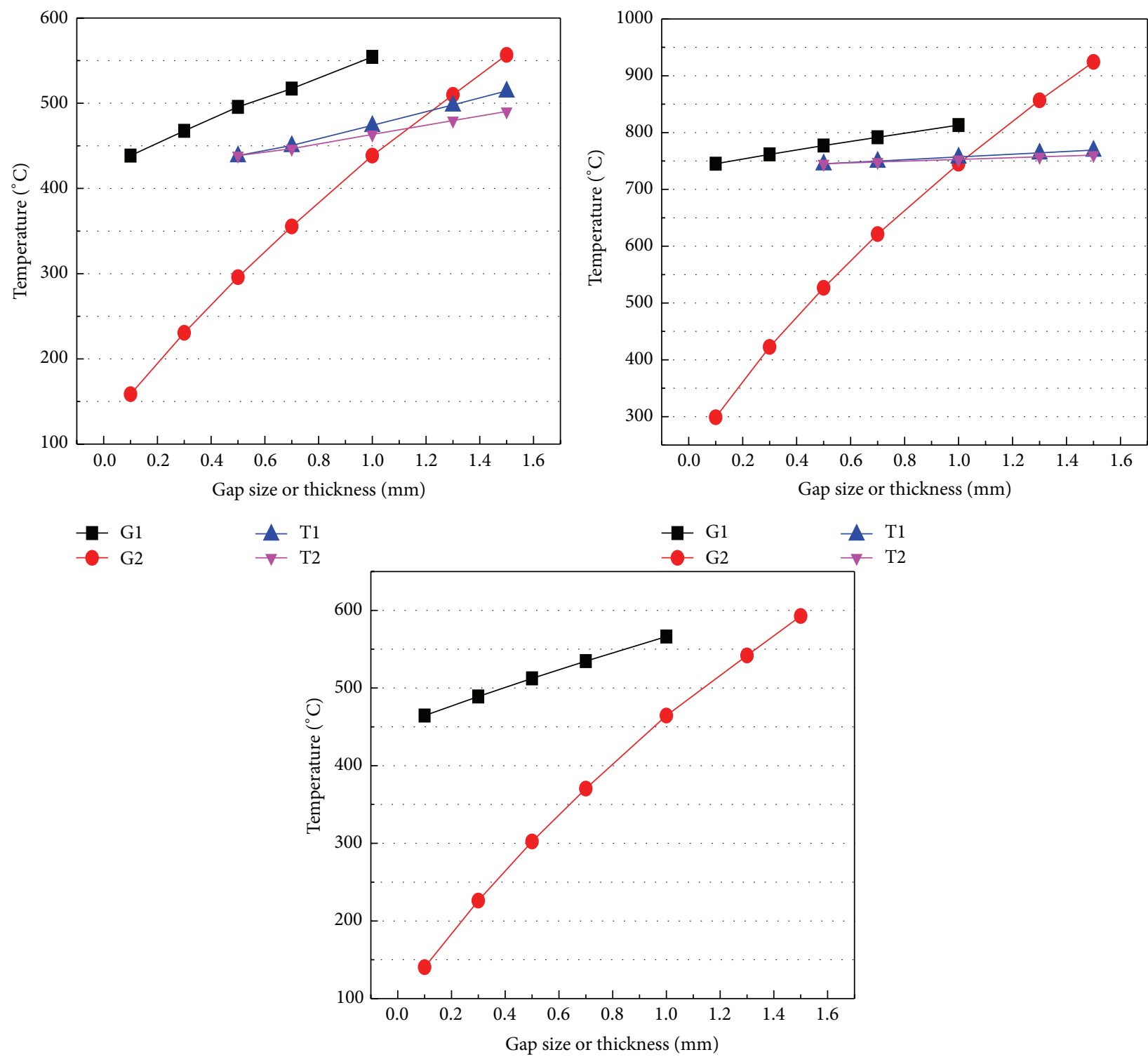

G1

G2

FIGURE 6: Effects of gaps G1 and G2 and container thicknesses T1 and T2 on the specimen temperature (from the left; capsule with NaK/LBE/Al thermal media).

used as the thermal media in a high-temperature irradiation capsule. In the case of a $\mathrm{NaK}$ capsule, to raise the temperature of the specimen to $950^{\circ} \mathrm{C}$, gap $\mathrm{G} 2$ of the NaK capsule should be $3.48 \mathrm{~mm}$, which is greater than the $1.575 \mathrm{~mm}$ gap in the LBE capsule. The capsule will be loaded into the irradiation hole of the reactor for testing. In HANARO, the capsule will be placed in the cooling water flowing upward with high pressure and high speed, and thus it will tremble with vibration. The vibration becomes larger as the gap between the parts in the capsule grows more. Because the gap between the parts in the NaK capsule is greater than that in the $\mathrm{LBE}$ capsule, the vibration increases more. It will be difficult to hold the parts in the capsule at a constant position and keep the temperature constant during the irradiation test.
In the helium gap between the inner container and the external tube, temperature falls sharply. The surface temperatures of the inner containers, $\mathrm{NaK}, \mathrm{LBE}$, and aluminum, reach as in Table 3. In accordance with the surface temperatures of the inner container, the radiation heat is transferred to the external tube contacting the cooling water. The radiation heat raises the temperature of the external tube as in Table 3 . The temperatures of the external tube are all low enough not to take place at the onset of nucleate boiling.

\subsection{Effect of Gaps G1 and G2 and Thicknesses T1 and T2 on the} Specimen Temperature. Figure 6 shows the effects of the gap size, G1 and G2, and thickness, T1 and T2, on the specimen's temperature in the capsule with $\mathrm{NaK}, \mathrm{LBE}$, and aluminum 

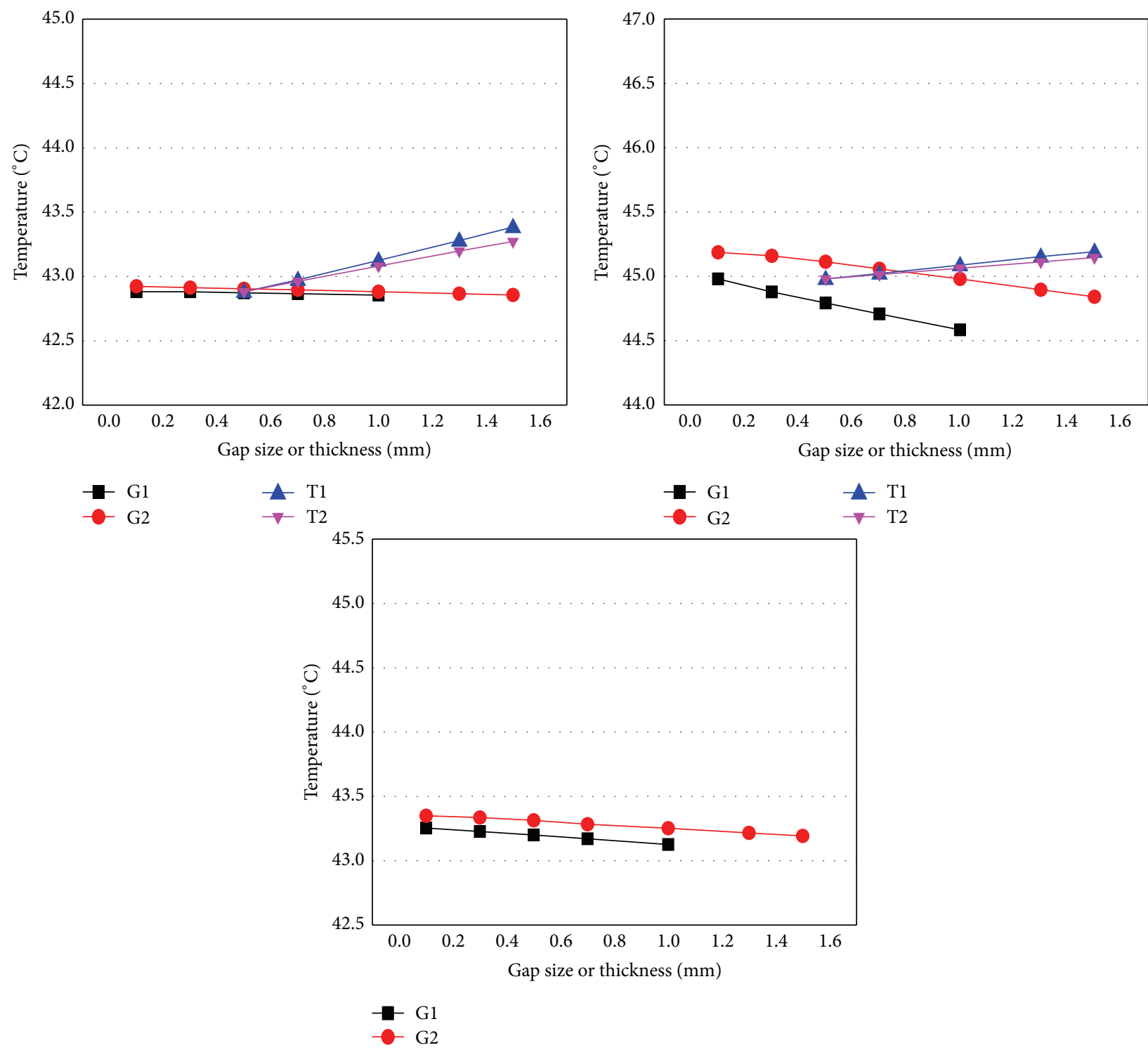

Figure 7: Effects of gaps G1 and G2 and container thicknesses T1 and T2 on the surface temperature (from left: NaK/LBE/Al thermal media).

thermal media. Among the 4 variables, the G2 effect is the most significant, and the effects of the others are very small. The steep gradients of the G2 curves indicate that heat is well transferred through thermal media in all cases. While gap G2 varies from 0.1 to $1.5 \mathrm{~mm}$, the temperature of the specimen changes from 150 to $550^{\circ} \mathrm{C}$ in $\mathrm{NaK}$, from 300 to $935^{\circ} \mathrm{C}$ in $\mathrm{LBE}$, and from 140 to $595^{\circ} \mathrm{C}$ in aluminum. Other variables such as G1, T1, and T2 do not have a great impact on the change in specimen temperature.

The effect of the thickness of the liquid container on the specimen's temperature is also analyzed and shown in the figure. The thickness of the liquid container, T1 and T2, changes from 0.5 to $1.5 \mathrm{~mm}$ in both cases. The temperature changes from 438 to $514^{\circ} \mathrm{C}$ in the $\mathrm{NaK}$ capsule and from 745 to $769^{\circ} \mathrm{C}$ in the $\mathrm{LBE}$ capsule. The variation rate in the $\mathrm{NaK}$ capsule is much bigger than in the LBE capsule. It indicates that the LBE is more stable than $\mathrm{NaK}$ on the specimen temperature according to the variation of the container thickness. This analysis showed that G2 plays an important role in determining the temperature of the capsule.

4.3. Effect of Gaps $G 1$ and $G 2$ and Thicknesses T1 and T2 on the Surface Temperature. Figure 7 shows the effects of the gap and container thickness on the surface temperature. Since the onset of nucleate boiling (ONB) on the capsule surfaces must be avoided, the surface temperature is quite important with respect to safety. From the figure, the effects of T1 and T2 get larger adversely as they increase. However, the effects are negligible since the temperature variations are within $2^{\circ} \mathrm{C}$. The surface temperatures in all cases meet the ONB criterion of HANARO, which should be less than $124^{\circ} \mathrm{C}$.

4.4. Effect of Gaps $G 1$ and $G 2$ and Thicknesses $T 1$ and $T 2$ on the Temperature Difference within a Specimen. Figure 8 

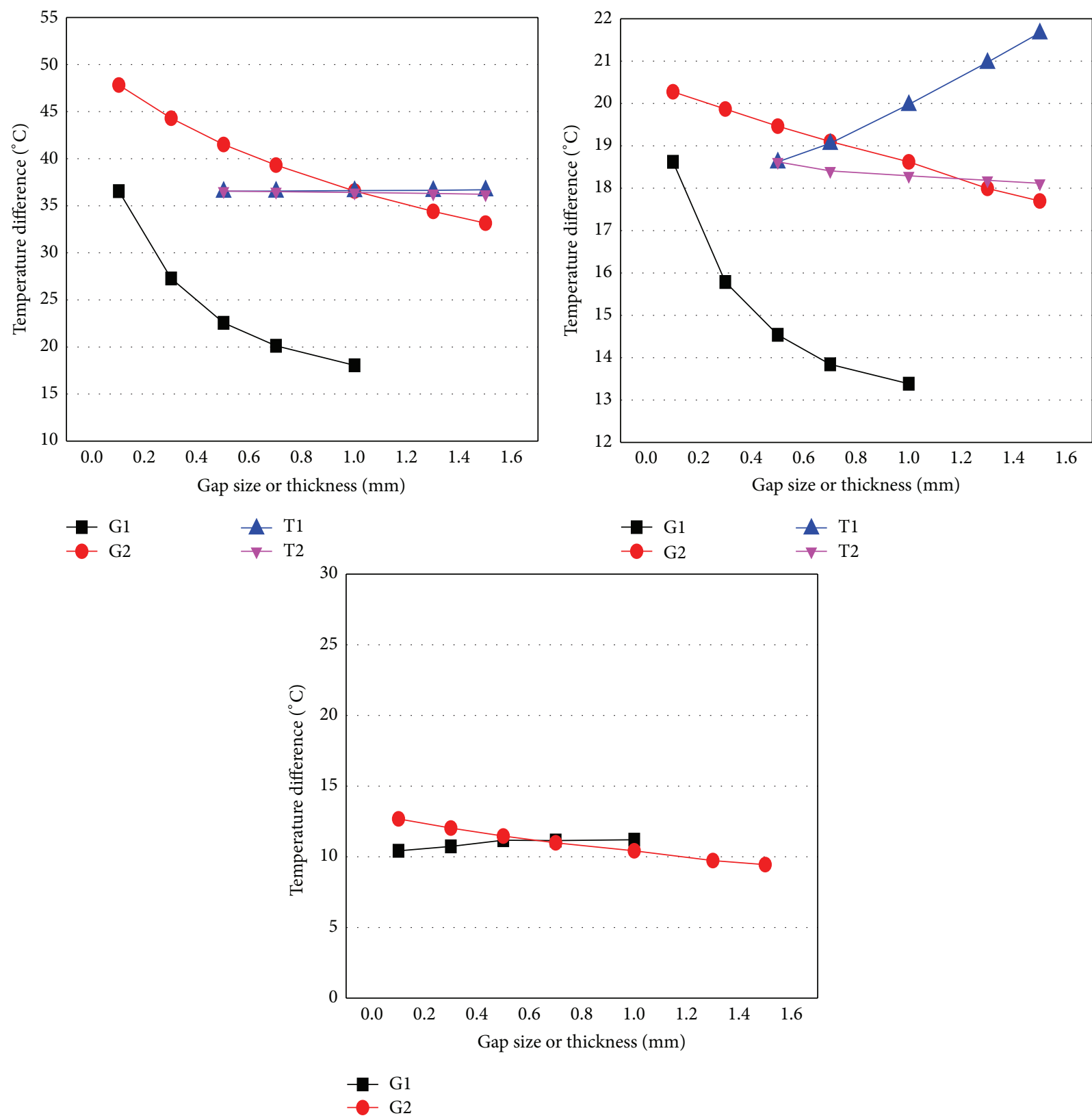

FIGURE 8: Effects of gaps G1 and G2 and container's thicknesses T1 and T2 on the temperature difference within the specimen (from left: $\mathrm{NaK} / \mathrm{LBE}$ /aluminum thermal media).

shows the effects of the gap and the container thickness on the temperature difference of specimens. The temperature difference within a specimen is one of the important parameters for the user requirements. The great temperature gradient within a specimen is detrimental to the irradiated properties. The temperature differences within the specimen during irradiation are usually required to be within $\pm 10^{\circ} \mathrm{C}$ in the case of a PWR reactor, which is currently operating at a temperature of $300^{\circ} \mathrm{C}$ all over the world. However, the coolant of a VHTR will be maintained at a temperature of $950^{\circ} \mathrm{C}$ which is much higher than that of a PWR. It will be appropriate to expand the temperature differences within the specimen during the irradiation test at up to $\pm 20^{\circ} \mathrm{C}$.
The optimal specimen size depends on the design configuration of a capsule as well as the nuclear characteristics of the test hole. The effect of the gap is larger than that of the container thickness. The temperature differences decrease according to the increase of the gap. G1 is much more sensitive to the difference in the specimen's temperature than G2, and both affect it adversely. On the other hand, the variations of T1 and T2 have little effect. From the analysis results, the larger gap size of G1 can cause a smaller temperature difference within the specimen. Since the increase in the gap raises the temperature of the specimen, although it lessens the temperature differences within the specimen, it is important to find the optimum gap sizes. The temperature differences within 
TABle 3: Temperature changes of the external tube by radiation heat.

\begin{tabular}{|c|c|c|c|c|}
\hline \multirow{2}{*}{ Thermal media } & \multirow{2}{*}{$\begin{array}{l}\text { Temperature of inner } \\
\text { container }\end{array}$} & \multirow{2}{*}{$\begin{array}{l}\text { Radiation heat to } \\
\text { external tube (W/g) }\end{array}$} & \multicolumn{2}{|c|}{ Temperature of external tube by radiation heat $\left({ }^{\circ} \mathrm{C}\right)$} \\
\hline & & & Before absorbing radiation heat & After absorbing radiation heat \\
\hline $\mathrm{NaK}$ & 867 & 5.61 & 53 & 59 \\
\hline LBE & 837 & 5.00 & 65 & 71 \\
\hline Aluminum & 906 & 6.38 & 55 & 62 \\
\hline
\end{tabular}

the specimen of an $\mathrm{Al}$ capsule are within the range of $\pm 10^{\circ} \mathrm{C}$, as shown in the right side of Figure 8 , although aluminum is not proper for high-temperature material irradiation. The temperature differences in a $\mathrm{NaK}$ capsule are in any case within the range of $\pm 11^{\circ} \mathrm{C}$ relative to the central temperature. However, the temperature differences in the LBE capsule are partially within the range of $\pm 20^{\circ} \mathrm{C}$. LBE is unfavorable in this respect in comparison with $\mathrm{NaK}$. In the case of a LBE capsule, it is desirable to make $\mathrm{G} 2$ greater than $0.7 \mathrm{~mm}$ to maintain the temperature difference of the specimen within $\pm 20^{\circ} \mathrm{C}$.

\section{Conclusion}

For irradiation of high-temperature materials to be used in a future nuclear system like a VHTR and SFR, a new type of capsule using liquid metal was reviewed for application to high-temperature irradiation tests. As an alternative to aluminum which has been used as the thermal media in a standard material capsule, the characteristics of liquid metals such as NaK and LBE are reviewed. The temperatures of the capsule are affected by the variation of parameters such as the gap and wall thickness of the container. In particular, the external gap G2 has the greatest influence on the temperature of the specimen, and thus G2 is the most important in determining the target temperature. The surface temperatures are almost constant regardless of any change in the gap and container thickness in all kinds of capsules. LBE raises the temperature of the specimen higher than $\mathrm{NaK}$ at the same configuration of the capsule. The LBE capsule can lessen the gap of the parts to reduce the vibration for a longterm stable test in the reactor. In addition, LBE has a higher boiling point and is convenient to treat in comparison with $\mathrm{NaK}$.

\section{Conflict of Interests}

The authors declare that there is no conflict of interests regarding the publication of this paper.

\section{Acknowledgment}

This work was supported by the National Research Foundation of Korea (NRF) grant funded by the Korea government (MSIP) (NRF-2013M2A8A1035822).

\section{References}

[1] T. Abram and S. Ion, "Generation-IV nuclear power: a review of the state of the science," Energy Policy, vol. 36, no. 12, pp. 43234330, 2008.
[2] A. Alemberti, "ALFRED the European lead fast reactor demonstrator," in Proceedings of the 5th Annual International Conference on Sustainable Development through Nuclear Research and Education, Pitesti, Romania, May 2012.

[3] K. L. Murty and I. Charit, "Structural materials for GenIV nuclear reactors: challenges and opportunities," Journal of Nuclear Materials, vol. 383, no. 1-2, pp. 189-195, 2008.

[4] J. Y. Park, "Possibility of fusion applications of current materials R\&D for GEN-IV nuclear energy system in KAERI," in Proceedings of the Korea-Japan Blanket Workshop, 2006.

[5] M. S. Cho, K. N. Choo, S. W. Yang, and S. J. Park, "Development of material capsules based on the irradiation temperatures in HANARO," in Proceedings of the 6th International Symposium on Material Testing Reactors, Bariloche, Argentina, October 2013.

[6] B. G. Kim, K.-N. Choo, J. M. Sohn, S. J. Park, Y. K. I. Kim, and Y. J. Kim, "Instrumentation for materials irradiation tests in HANARO,” Nuclear Technology, vol. 173, no. 1, pp. 56-65, 2011.

[7] K. N. Choo, B. G. Kim, M. S. Cho, Y. K. Kim, and J. J. Ha, "Measurement and evaluation of the irradiation test parameters for a specimen in a HANARO material irradiation capsule," IEEE Transactions on Nuclear Science, vol. 57, no. 5, pp. 2642$2646,2010$.

[8] K.-I. Fukumoto, M. Narui, H. Matsui, K. Ito, and Y. Yano, "Development of irradiation capsules in liquid metal environment in Joyo and their application to irradiation creep measurement of Vanadium alloys," Journal of Nuclear Science and Technology, vol. 45, no. 2, pp. 171-178, 2008.

[9] B. A. Pint, J. L. Moser, and P. F. Tortorelli, "Liquid metal compatibility issues for test blanket modules," Fusion Engineering and Design, vol. 81, no. 8-14, pp. 901-908, 2006.

[10] S. V. Stankus, R. A. Khairulin, A. G. Mozgovoy, V. V. Roshchupkin, and M. A. Pokrasin, "The density and thermal expansion of eutectic alloys of lead with bismuth and lithium in condensed state," Journal of Physics: Conference Series, vol. 98, Article ID 062017, 2008, Proceedings of the 13th International Conference on Liquid and Amorphous Metals.

[11] Nuclear Energy Agency (NEA), Gen-IV International Forum Annual Report, Nuclear Energy Agency (NEA), Paris, France, 2014.

[12] C. V. Madhusudana, "Gap conductance at the interface," in Thermal Contact Conductance, Mechanical Engineering Series, chapter 4, pp. 55-77, Springer, 2nd edition, 2014.

[13] Y. S. Lee, M. H. Choi, and Y. H. Kang, "Thermal and mechanical characteristics of an instrumented capsule for a material irradiation test," Nuclear Engineering and Design, vol. 205, no. 1-2, pp. 205-212, 2001. 


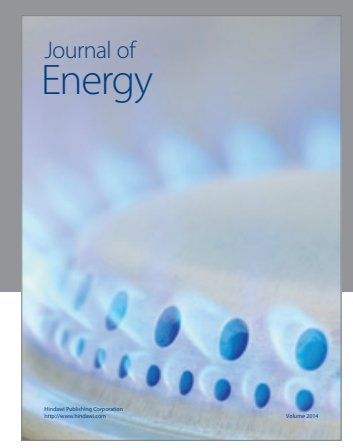

Journal of

Industrial Engineering
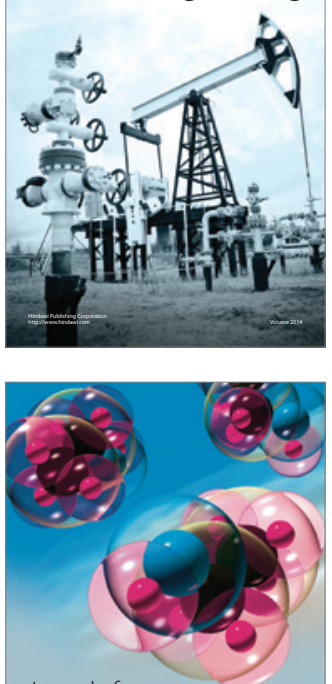

Fuels
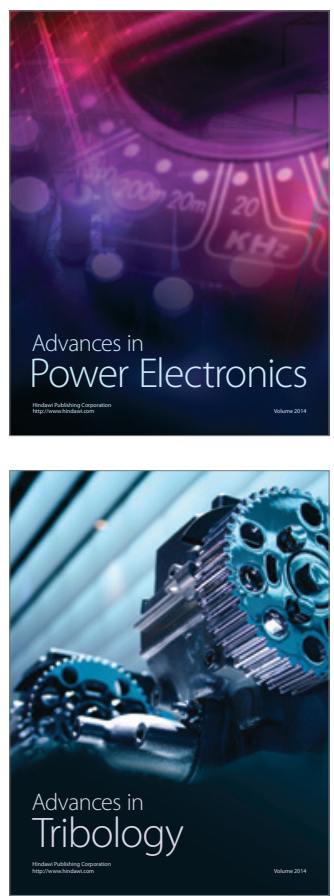

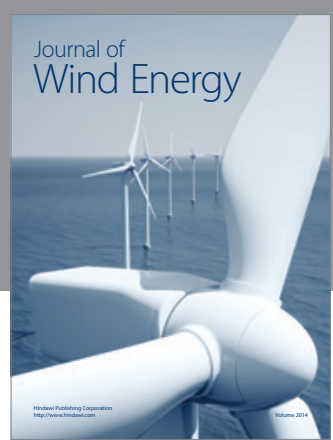

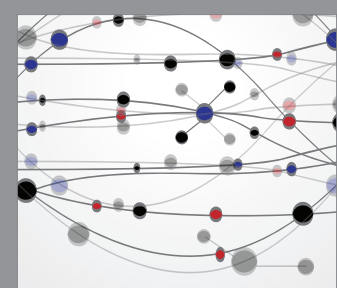

The Scientific World Journal

Submit your manuscripts at http://www.hindawi.com

Journal of

Structures
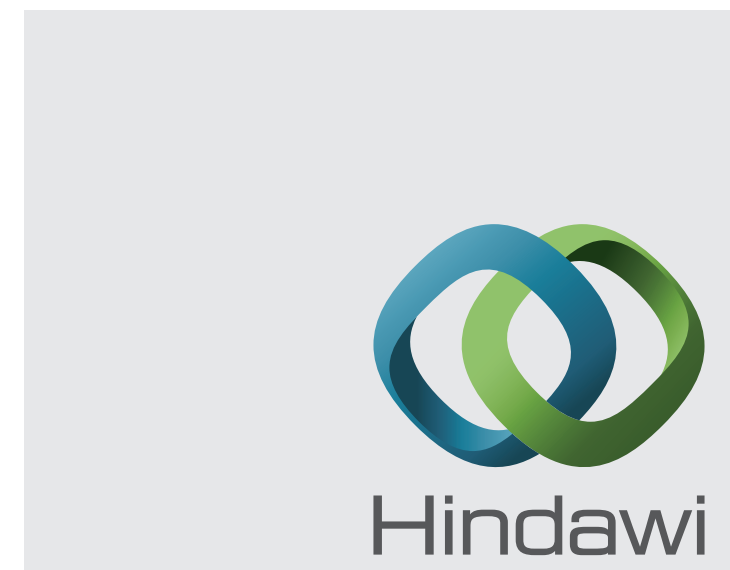

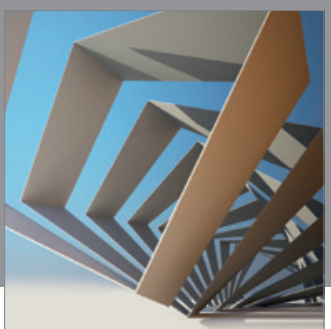

Rotating

Machinery
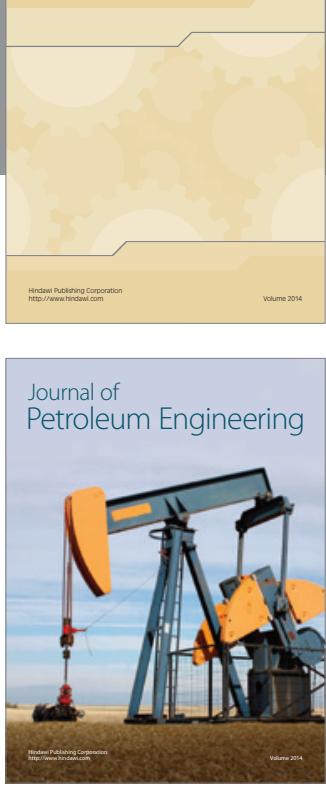

Journal of

Solar Energy
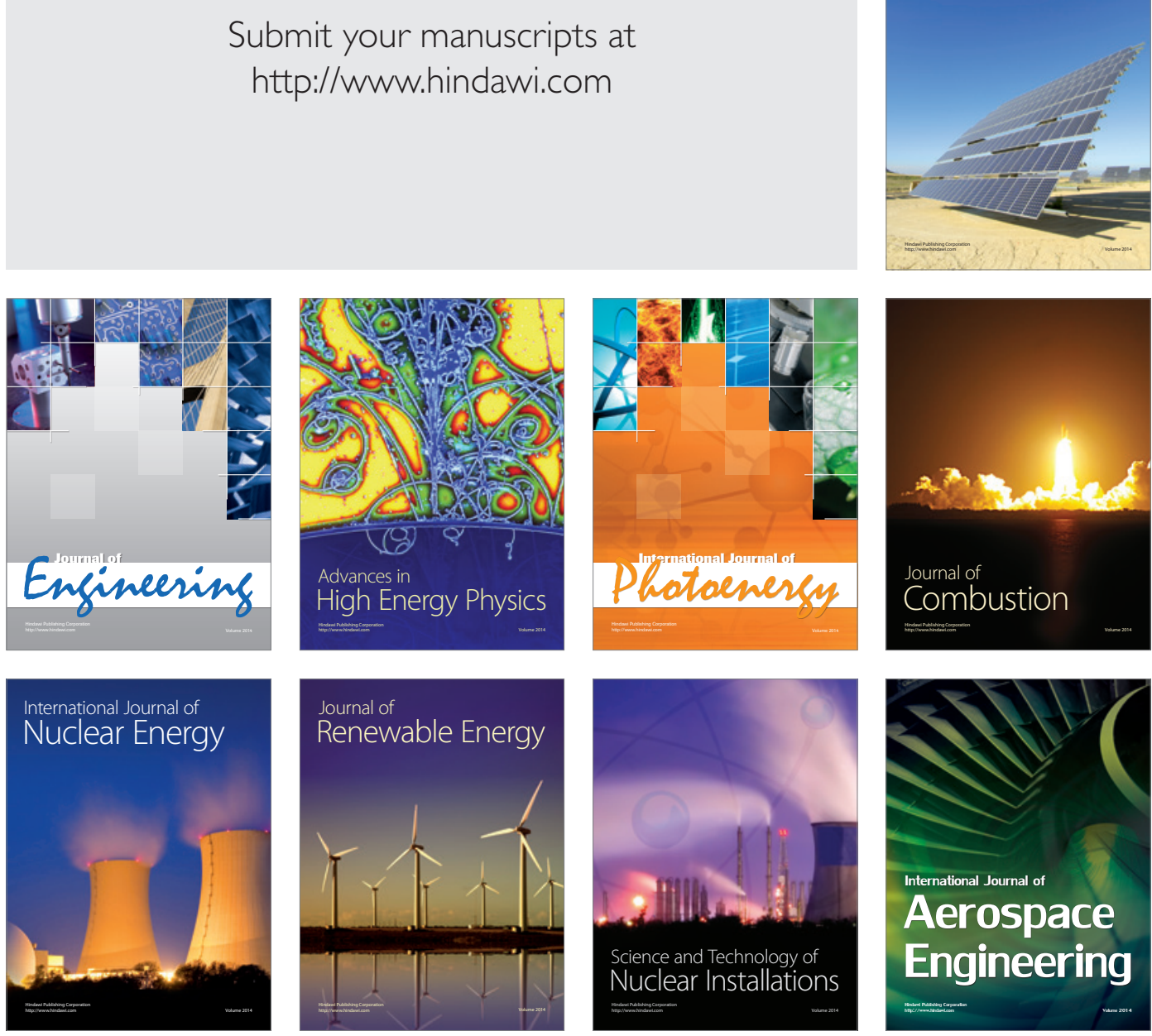